\title{
Analysis of Vulnerability to Poverty and Income Shocks of Households in Rural Nigeria
}

\author{
Adepoju A. A. ${ }^{*}$, Ayantoye $\mathrm{K}^{2}$., Amao J. O. ${ }^{1}$, Akinjobi G. A \\ ${ }^{1}$ Department of Agricultural Economics, Ladoke Akintola University of Technology, Ogbomoso, Nigeria \\ ${ }^{2}$ Department of Agricultural Eeconomics and Extension, Kwara State University, Malete, Kwara State Nigeria \\ ${ }^{*}$ Correspondence : aaadepoju@lautech.edu.ng ; busolaadepoju@gmail.com
}

\section{ABSTRACT}

The study looked at the poverty profile of households in rural Nigeria and also their vulnerability to poverty and factors determining vulnerability to poverty. The study used the post harvest and post planting cross section data from the National Living Standard Survey (NLSS) for year 2012. A multi-Stage sampling technique was adopted to select a total of 1020 households for the study. Three stage feasible generalized least square (3FGLS) estimation procedure was used to analyze the vulnerability to poverty and to model the effect of household socio-economic status on expected future consumption and variation in future consumption while Tobit model was used to examine the determinants of vulnerability to poverty and VEP. The result revealed that 58 percent of the rural household in the study area are poor, and the intensity of poverty was 30.1 percent, which was high for the study area was high. Severity of poverty was recorded as 18.4 percent, an indication for income inequality among the poor. The result further revealed that age squared $(P=0.01)$, sex $(P=0.10)$, covariate shocks $(\mathrm{P}=0.10)$ and farm size $(\mathrm{P}=0.05)$ were positively significant in ex ante mean consumption while age $(P=0.01)$, married respondents $(P=0.10)$, and years of schooling $(P=0.05)$ were negatively significant in ex ante mean consumption. The shocks variables experienced by households in the study area were natural/agricultural; economic; political/social/legal; and demographic/life-cycle shocks that inflict welfare loss. The findings suggest that poverty and vulnerability to poverty are independent concepts. It is recommended that policies concerning poverty reduction should consider households that are currently nonpoor but are vulnerable to poverty along with poor households. Rural households should also be encouraged to engage in more off-farm activities and value addition of their produces.

Keywords : Vulnerability, Poverty, Household, Household Resilience, Ex-Ante.

\section{INTRODUCTION}

The issue of whether or not a household is poor is widely recognized as an important, though crude indicator of a household's well being. This is reflected in the central role the concept of poverty plays in analysis of social protection policy (Oni and Yusuf, 2006). In recent years, however, the term vulnerability has come to be widely used alongside poverty in discussions of poverty alleviation and social protection strategies (Oni and Yussuf 2008). Policies in Nigeria aimed at improving the wellbeing through poverty reduction tend to target the current poor to the neglect of the vulnerable. While it is important to focus on poverty, there is a growing recognition that reducing just the level of poverty may not be a wholly satisfactory approach to development (Alayande and Alayande, 2004). According to Sen (1999) the challenge of development includes not only the elimination of 
persistent and endemic deprivation, but also the removal of vulnerability to sudden and severe destitution. Although the new emphasis has lead to an increased attention on vulnerability, important questions about what we exactly mean by vulnerability, and how we should measure vulnerability remains open.

A household's vulnerability to poverty at any point in time depends on how its livelihood prospects and well-being is likely to evolve over time. And that in turn depends on its future income prospects, the degree of income volatility it faces, its ability to smooth consumption in the face of income or other livelihood shocks. These in turn depend on the complex dynamic inter linkages between the environment-macroeconomic, institutional, sociopolitical and physical-in which the household operates, the resources, human, physical and financial it commands, and its behavioral responses (Chaudhuri, 2003).

In another dimension today's poor may or may not be tomorrow's poor. Currently non-poor households, who face a high probability of a large adverse shock, may, on experiencing the shock, become poor tomorrow. And the currently poor households may include some who are only transitorily poor as well as other who will continue to be poor (or poorer) in the future. This definition would be adopted for this study. Vulnerability assessments, by definition, have to be explicitly forward-looking. No matter how rich the data, the vulnerability of households is never directly observable. In contrast, most poverty assessments are couched in temporal terms and, given the right data, it is possible to actually observe the current poverty level or status of the household (Chaudhuri, 2003).

The correlation between vulnerability and poverty can only be stressed when the vulnerability of different segments of the population are to be assessed at present and in the near future. In this connection, household's vulnerability will be perceived as the probability that the household will experience poverty in the near future. It is also important to note that changes in vulnerability are broadly consistent with poverty trends (Bidani and Richter, 2001). This is why the term vulnerability is presently being used alongside poverty in discussing poverty alleviation and social protection policies.Omonona (2001) identified the sources of poverty among rural farming households in Nigeria. On the other hand, Alayande (2003) carried out a vulnerability assessment of Nigeria. The study identified rural Nigerians as the most vulnerable to poverty. The study however failed to provide information on expected poverty profile of rural Nigerians using idiosyncratic and covariate variables or shocks.

This study therefore determines the vulnerability to poverty status of households in rural Nigeria and examines the income shocks experienced by households in rural Nigeria.It also assess income shocks, its characteristics and constraints on the poor and vulnerable for formulating effective strategies aimed at reducing poverty and improving social protection programmes in Nigeria.

\section{Literature Review/Empirical Framework}

In recent times, researchers have carried out studies on vulnerability. Isabel and Johannes (2012), argued that the recent evidence on individuals' decision making is of high relevance for the measurement of poverty when switching from a static and certain to a dynamic and uncertain framework. The numerous proposed measures of multi-period poverty and vulnerability have until now not taken into accounts the insights from behavioral economics. Alayande and Alayande (2004) attempted a quantitative and qualitative assessment of vulnerability to poverty in 
Nigeria. In qualitative terms, they noted that weak governance structure in the form of absence of rule of law, lack of political effectiveness and efficiency and high level of insecurity were major sources of vulnerability to poverty in Nigeria. In like manner, Mccathy et al (2016) measures vulnerability to poverty in rural Malawi, the results show that in 2010 two-fifths of all households had a chance of at least 40 percent of falling below the poverty line in the future. The results show that many households in rural Malawi are vulnerable to poverty.

In the micro-econometric literature, approaches to assessing vulnerability can be divided in three broad categories. The first one construes vulnerability as expected poverty (VEP). Along this line are authors like, Pritchett, Suryahadi, and Sumarto (2000), Chaudhuri, Jalan, and Suryahadi (2002), Christiansen and Subbarao (2005). Pritchett, Suryahadi and Sumarto (2000) understand vulnerability to poverty as having experienced poverty during a certain period of time $t$, over a relevant span $t=-\infty, \ldots .,-2,-1,0$, or the probability of experiencing poverty in the near future. For Chaudhuri, Jalan and Suryahadi (2002), vulnerability to poverty is the probability to become or remain poor at time $\mathrm{t}+1$, given certain socioeconomic characteristics at time t. In turn, Kasirye's (2007) perception of vulnerability to poverty is the absence of households' resilience to shocks that can bring welfare below a threshold deemed acceptable by society.

The latter two definitions are admittedly more forward looking. In any case, the most commonly adopted definition in the academia is the probability of an individual or household to fall into poverty. While knowing the probability to fall into poverty may be preferable to a mere static assessment of poverty, it is arguably desirable that a vulnerability measure provide a complete picture to discern between those facing the risk of falling into poverty, those with the ability to move out of poverty, and the ones with so weak fundamental circumstances that they are trapped into poverty. Formally, and letting $\mathrm{V}_{\mathrm{it}}$ be the probability of expected poverty of household $i$ at time $t$, then one functional form to represent vulnerability, as is given in Chaudhuri, Jalan, and Suryahadi (2002), can be posited according to $(1)$

$V_{i t}$

$=\int_{\beta+1}\left(\int^{z} d F\left(y_{i, t+1} \mid X_{i}, \beta_{t+1}, \alpha_{i,} \varepsilon_{i, t+1}\right)\right) d G\left(\beta_{t+1} \mid \beta_{t}\right)$

Where $\mathrm{dF}(\cdot \mid \cdot)$ is the cumulative density of $\mathrm{y}_{\mathrm{i}, \mathrm{t}+1}$ conditional on $\left(\mathrm{X}_{\mathrm{i}}, \beta_{\mathrm{t}+1}, \alpha_{\mathrm{i}}, \varepsilon_{\mathrm{i}}, \mathrm{t}+1\right)$ and $\mathrm{dG}(\cdot \mid \cdot)$ is the cumulative density of $\beta_{t+1}$ conditional on $\beta_{\mathrm{t}}$. Equation (1) can be written in a much more empirically implementable fashion as in (2)

$$
\begin{aligned}
V_{i t}=\operatorname{Pr}\left(y_{i, t+1}\right. & =y\left(X_{i}, \beta_{t+1}, \alpha_{i,} \varepsilon_{i, t+1}\right) \\
& \left.\leq z / X_{i}, \beta_{t}, \alpha_{i,}, \varepsilon_{i t}\right)
\end{aligned}
$$

where $\mathrm{y}$ is a welfare measure (either consumption or income), and $\mathrm{z}$ is the societal benchmark (the poverty line). Xi contains vectors of household characteristics, $\beta t$ is a vector of parameters, $\alpha$ is atemporal

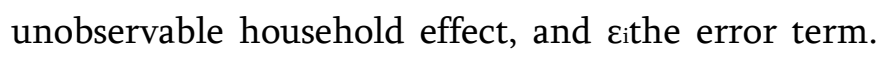
Equation (2) therefore, is the probability that a household will be poor in period $\mathrm{t}+1$ given her fundamental circumstances in period $t$. An extension of (2) to account for more than one period had been proposed by Pritchett, Suryahadi, and Sumarto (2000). The risk of household $i$, represented by $R(\cdot)$ ) is the probability that at least in one spell household's welfare will be below the societal benchmark. This can be expressed as follows:

$$
\begin{aligned}
R_{i}(n, z)=1- & \left\{\left[\left(1-\operatorname{Pr}\left(y_{i, t+1}\right)\right.\right.\right. \\
& <z), \ldots,\left(1-\operatorname{Pr}\left(y_{i, t+n-1}\right)\right. \\
& \left.\left.<z),\left(1-\operatorname{Pr}\left(y_{i, t+n}\right)<z\right)\right]\right\}
\end{aligned}
$$

where $\mathrm{y}_{\mathrm{t}+\mathrm{i}}, \mathrm{i}, 1,2, \ldots, \mathrm{n} 1,,=-\mathrm{n}$ are measured in constant terms throughout the $\mathrm{n}$ periods. Equation (3) implies that the degree of vulnerability of household $i$ is equal to 1 minus the probability of no episodes of poverty. Given a probability threshold (setexogenously) $p$, the authors determine a household to be vulnerable if the probability shefaces 
is greater than $p$ during $\mathrm{n}$ periods. Formally, this can be represented as given below:

$V_{i t}(z, n ; p)=I\left[R_{i t}(z, n)>p\right]$

The ith,I [ $\cdot]$ being an indicator function equal to 1 if the condition in the right hand side of (3) is true, and zero otherwise. Results based on this approach and related ones can lead to very odd conclusions. As Ligon and Schechter (2003) put it, a mean preserving spread at the lower tail of the distribution, increasing therefore risk exposure for households in that section of the distribution, makes vulnerability, when construed as expected poverty, decline. To remedy such a drawback the authors make use of an expected utility approach to defining vulnerability as low expected utility (VEU). Defining $\mathrm{U}_{\mathrm{i}}$ as a strictly increasing and weakly concave utility function, Ligon and Schechter (2003) posit the vulnerability of household i as follows:

$$
V=U_{t}\left(y^{e}\right)-E U_{i}\left(y_{i}\right)
$$

where $\mathrm{y}^{\mathrm{e}}$ (a poverty line) is defined by the authors as a certainty equivalent income level above which a household would be considered non vulnerable. $\mathrm{y}^{\mathrm{e}}$ is set in such a way that inequality among individuals is zero. That is, it is the expected income realization homogenized by some convenient equivalence scale. E stands for expectation. Equation (5) can be rewritten as follows:

$$
\begin{aligned}
V_{i}=\left[U_{i}\left(y^{e}\right)-\right. & \left.U_{i}\left(E y_{i}\right)\right] \\
& +\left[U_{i}\left(E y_{i}\right)-\left(y_{i}\right)\right]
\end{aligned}
$$

where the first term in the right hand side is a utility gap measure (i.e. poverty) and has all the properties of the FGT $\alpha$ class of poverty measures. In turn, the second term represents the risk (shock) faced by household i. This latter term can be decomposed into idiosyncratic and covariate risks, as is captured by (7).

$$
V_{i}=\underset{\text { Poverty }}{\left[U_{i}\left(y^{e}\right)-U\left(E y_{i}\right)\right]} \longrightarrow+\underset{\text { Idiosyncratic risk }}{\left[\left[E U_{i}\left(E y_{i} \mid \bar{x}\right)-E U_{i}\left(y_{i}\right)\right]\right\}}+\underset{\text { Covariate risk }}{\longrightarrow}
$$

The authors further decompose to account for possible measurement error that would otherwise bias idiosyncratic risk to yield equation [8]:

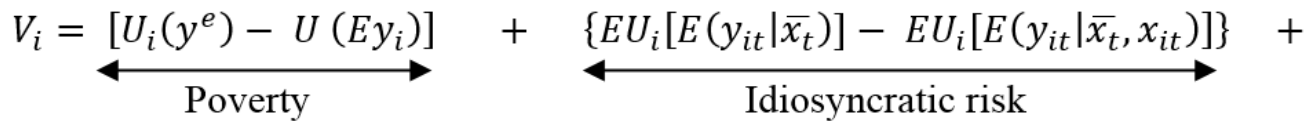

$$
\begin{aligned}
& +\underset{\text { Covariate risk }}{\left\{U_{i}\left(E y_{i t}\right)-E U_{i}\left[E\left(y_{i t} / \overline{x_{t}}\right)\right]\right\}}+\underset{\text { Measurement error and unexplained risk }}{\stackrel{\left\{E U_{i}\left[E\left(y_{i t} \mid \overline{x_{t}}, x_{i t}\right)\right]-E U_{i} y_{i t}\right.}{\longmapsto}}
\end{aligned}
$$

\section{METHODS AND MATERIAL}

After adequately choosing a functional form for $\mathrm{U}_{\mathrm{i}}$ and a way to estimate the conditional expectations, regressing each part of the Equation (8) on household and community characteristics leads to the correlates of vulnerability. Christiansen and Subbarao (2005) criticize this approach to measuring vulnerability as expected utility on the grounds that it put individual risk preferences at the forefront of vulnerability assessment. Admittedly, adverting to risk attitudes in vulnerability assessment may in a way be against the very principle of equality of opportunity. Adopting such an approach implies that risky individuals who are affected adversely by some shock inherent with their choices would be treated favorably when policies are designed to help those that are identified as vulnerable (Jadotte 2010).

The third approach construes vulnerability as uninsured exposure to risk-VER Under this framework vulnerability is defined as the inability to smooth consumption over time, given the presence of shocks. In such a case, no specific vulnerability 
measure is estimated. Many different models to measure vulnerability as uninsured exposure to risk can be found in the literature but the general form adopted is the following:

$$
\begin{aligned}
\Delta \ln y_{i t}=\beta X_{i} & +\sum \gamma s_{t} \\
& +\sum \delta S_{t}+\sum \lambda \mathrm{D}+\Delta \varepsilon_{i t} \ldots
\end{aligned}
$$

Where $\Delta \ln y_{i t}$ is the income growth rate, $s$ and $S$ are idiosyncratic and covariate shock respectively. $\mathrm{D}$ is a set of administrative region dummies, and $\varepsilon$ is an error term. Finally, $\beta, \gamma, \delta$, and $\lambda$ are parameters to be estimated. It is straightforward that the income generating process of a household not subject to shocks can be represented by (10)

$$
\Delta \ln y_{i t}=\beta X_{i}+\sum \lambda \mathrm{D}+\Delta \varepsilon_{i t}
$$

So, the net effect of idiosyncratic and covariate shock, as is captured by $\gamma$ and $\delta$, is given by subtracting (10) from (9). The shortcoming with such an approach is that, when fluctuations in the lower tail of the distribution are low, which is often the case, poor households may not be considered vulnerable (Christiansen and Subbarao, 2005). By the same token, non-poor households with risky assets (e.g. investment in the stock market) may be counted as vulnerable due to the high probability of adverse shocks their wealth is subject to. Chaudhuri (2003) also sustains that vulnerability measures that focus on consumption smoothing ability ignore the asymmetry of shocks, while Ligon and Schechter (2003) contend that vulnerability to shocks does not depend directly on household income (or consumption) level under this approach. The methodology adopted for this research follows Chaudhuri, Jalan, and Suryahadi (2002) and and Günther and Harttgen (2009), which is vulnerability as expected poverty (VEP).
In principle, two empirical approaches to determine this probability could be pursued. First, one could try to specify for each household future states of the world, determine their likelihood and the income attached to them and calculate vulnerability to poverty in this way (Landau et al 2012). This is done in Povel (2015) which uses information on perceived probabilities of future shocks and their severity as stated by households. While this is an interesting approach, it makes strong assumptions about the ability of households to judge risks and their impact accurately and it assumes independence of risks. A second approach, common in the literature, has been to determine vulnerability to poverty by predicting incomes based on covariates. In this approach the probability $v_{n}^{(h)}$ is usually estimated using regression models (e.g. Chaudhuri et al. (2002), Christiaensen and Subbarao (2005)) in which covariates $X_{t}^{(h)}$ are mainly household characteristics, but also macro or climate variables (e.g. Christiaensen and Subbarao (2005)) or possibly income / consumption in previous years. If panel data are available then it is possible to capture some of the dynamic structure of vulnerability. However, if the model for income is of the form:

$$
y_{t}^{(h)}=X_{t}^{(h)}+e_{t}^{(h)}
$$

then, in order to estimate $v_{n}^{(h)}$, it is first necessary to forecast the future values of the covariates. Here the $e_{n}^{(h)}$ represent the residuals in the model, interpreted as positive or negative "shocks", or deviations from the expected income. In the case where only cross sectional data are available, several additional and stringent assumptions are needed to estimate vulnerability. In particular we need to assume that vulnerability remains constant over time, that neither the household covariates nor the expected income change over time. Only the residuals (shocks) change. In effect this model assumes that the inter-temporal 
variance can be measured using the cross-sectional variance, and that shocks are serially uncorrelated (Landau et al 2012).

\section{METHODOLOGY}

Study area: The study was carried in Nigeria, the most populous country in Africa and nineth most populous country in the world. According to FRN,(2007) the population of Nigeria rose from about 88.5 million in 1991 to 140 million in 2006 and to 168.8 million in year 2012 (World Bank 2012). The precise study area of this study is rural Nigeria whose population estimate as reported by World Bank 2012 is $77,803,783$ in 2010. Nigeria is dived into 6 geopolical zones namely, North central, North East, North West, South West, South South and South East.

Sampling Technique: The secondary data used for this study was obtained from the National Living Standard Survey (NLSS)of year 2012/2013.A multi-stage sampling technique was adopted for this study. The first stage is a random selection of two states from each six geo-political zones we have in Nigeria. The states selected were Plateau, Kwara, Bauchi, Gombe, Katsina, Zamfara, Ebonyi, Crossriver, Delta, Osun and Ondo. The second stage was the selection of 102 Enumeration Areas (EAs). The third stage is the random selection of ten (10) households in each Enumeration Area. In all, a total of 1020 households were for the study.

Data analysis: Three step generalized least square (FGLS) estimation procedure was used to analyze the vulnerability to poverty and to model the effect of household socio-economic status on expected future consumption and variation in future consumption. VEP vulnerability as expected poverty approach was used to measure vulnerability.
Vulnerability as expected poverty: Taking into account the dynamic dimensions of poverty, the measure of Vulnerability as Expected Poverty (VEP), an $e x$ ante measure proposed by Chaudhuri et al.,(2002) was adopted as used by Dawit, (2015), Birhan and Testahun, (2017) and Sisay et al, (2016) because of the advantage of the VEP approach especially in terms of its ability to identify households that are exposed to risks but who are not poor. Vulnerability in this approach is defined as the probability of being poor in the future and basically can take on two forms. It is either the ex ante risk that a household that is currently not poor will fall below the poverty line or the risk that a household that is currently poor will remain poor. This can be formally expressed as:

$$
V_{t}=\operatorname{Prob}\left(C_{(t+1)}<Z\right)
$$

Where the vulnerability of a household during the current period $\mathrm{V}_{\mathrm{t}}$ is dependent on the probability that future household consumption $\mathrm{C}_{(\mathrm{t}+1)}$ will be less than poverty line (Z). Empirically, building on the works of Chaudhuri etal.,(2002) and Gaiha et al., (2007), VEP was obtained by the following procedure: First, the FGT measure of headcount poverty (Foster, et al., 1984) was estimated from household data. Second, household's expected consumption and its variance of the error term was estimated using the 3 stage Feasible Generalized Least Square (FGLS) estimation procedure. Household's vulnerability to poverty was then derived as the conditional probability of the household falling into poverty in the next period or the probability that a household's consumption lie below the predetermined poverty line in the near future.

$V \hat{E} P_{i}=\widehat{v}_{l}=\widehat{P}_{l}\left(\operatorname{In} c_{i}<\operatorname{In} z \mid X_{i}\right) \emptyset\left(\frac{\operatorname{In} z-X_{i} \widehat{\beta}}{\sqrt{X_{i} \widehat{\theta}}}\right)$

The standard vulnerability threshold of 0.5 was adopted following (Gahia et al., 2007; Imai et al., 2009; 
Oni and Yusuf, 2006) where households were classified into their vulnerability status. Hence, those with a 50 per cent or more chance of falling into poverty in the future were identified as vulnerable.

\section{Results and Discussion}

\section{A. Socioeconomic characteristics of the respondents}

The socio economic characteristics of the respondents are presented in Table 1. The table revealed that 34.12 percent of the respondents' ages accounting for the highest percentage were between $41-50$ years. This is closely followed by those within the age bracket 5160 years, recording 33.23 percent. The least in the age bracket were respondents that were 30 years and below which accounted for only 2.07. The mean age of the respondents was 50.6 years; this implied that most of the respondents were in their active age but tending towards old age. This contradicted the findings of Olaolu et al., (2013) where the average age of the respondents was 45.5 years. The table also showed the proportion of the households headed by a male as 84.12 percent, while 15.88 percent of the households were female-headed. The result indicated that most of the household was headed by a male. This corroborated the findings of Maharjan and Joshi (2009) in their study on "Relationship between Income-poverty and Food Insecurity in Rural FarWestern Mid-hill of Nepal", where the male-headed families were about 88.3 percent.

About 82.34 percent of the respondents were married, 14.79 percent were widows, 2.47 percent were separated and only 0.39 percent was divorced. This is an indication that all the respondents have been marriedat a point in time of the other. The high percentage of married people is an indication of more responsible farming households in the study area, which implied that the respondents enjoyed the support of their spouses and children. This support may help in combating the problem of poverty in the study area. This finding echoed the result of Adepoju and Obayelu (2013) who worked on livelihood diversification and welfare of rural households in Ondo State, Nigeria where about 81.8 percent of the respondents were married. Considering household size, households with 6-10 members were 48.52 percent; while households with less than six members accounted for 40.53 per cent. It is worthy to note that households with more than ten members recorded the least percentage having a figure of 10.95 percent. The mean household size was found to be seven. This indicated that rural households in the study area were fairly large. Large household might be contributing to the depth of poverty in the study area. However, this is small relative to the findings of Olaolu et al., (2013) where the average household size was approximately 11 persons.

About 50 percent of the respondents had farm size that is not more than 5 ha, 25. 64 percent had farm size ranging between 6-10 ha of farmland, while 24.26 percent had more than 10 acres to cultivate. The average hectare owned by the respondents was 8.16 hectares; this indicated that most farming households had a considerable farm size to cultivate. Efficiency in production and processing of their farm produce might go a long way in combating poverty. This result shows an improvement on the findings of Ahmed and Abah (2014) where 46.6 percent households have between 2 and 3.99 hectares of farmland.

Table 1 further revealed that 66.07 percent of the farmers had no formal education, 10.45 percent had only primary school education, while 8.28 percent accounted for those respondents that had secondary school education. The result showed that most of the respondents in the study area had no formal education. This might be an integral part of the main reason of the causes of poverty incidence in the study area. The findings is contrary to the result of Amao et 
al., (2017) where a study on analysis of poverty status in Imo State, Nigeria reveals that most of the and income distribution among farming households respondents had one form of education or the other.

Table 1 : Socioeconomic characteristics of the respondents

\begin{tabular}{|c|c|c|c|}
\hline Socioeconomic variables & Frequency & Percentage & Mean \\
\hline \multicolumn{4}{|l|}{ Age (years) } \\
\hline$<=30$ & 21 & 2.07 & \\
\hline $31-40$ & 161 & 15.88 & \\
\hline $41-50$ & 345 & 34.02 & 50.6 \\
\hline $51-60$ & 337 & 33.23 & \\
\hline Above 60 & 150 & 14.79 & \\
\hline Total & 1014 & 100.00 & \\
\hline \multicolumn{4}{|l|}{ Gender } \\
\hline Female & 161 & 15.88 & \\
\hline Male & 853 & 84.12 & \\
\hline Total & 1014 & 100.00 & \\
\hline \multicolumn{4}{|l|}{ Household size } \\
\hline Not more than 5 & 411 & 40.53 & \\
\hline $6-10$ & 492 & 48.52 & 7 \\
\hline Above 10 & 111 & 10.95 & \\
\hline Total & 1014 & 100.00 & \\
\hline \multicolumn{4}{|l|}{ Marital status } \\
\hline Divorced & 4 & 0.39 & \\
\hline Married & 835 & 82.34 & \\
\hline Separated & 25 & 2.47 & \\
\hline Widowed & 150 & 14.79 & \\
\hline Total & 1014 & 100.00 & \\
\hline \multicolumn{4}{|l|}{ Farm size (acres) } \\
\hline Not more than 5 & 508 & 50.10 & \\
\hline $6-10$ & 260 & 25.64 & 8.16 \\
\hline Above 10 & 246 & 24.26 & \\
\hline Total & 1014 & 100.00 & \\
\hline \multicolumn{4}{|l|}{ Education status } \\
\hline None & 670 & 66.07 & \\
\hline Primary & 106 & 10.45 & \\
\hline Secondary & 84 & 8.28 & \\
\hline Tertiary & 154 & 15.19 & \\
\hline Total & 1,014 & 100.00 & \\
\hline
\end{tabular}

Source: Author's estimates based on the GHS data 2012/2013.

\section{A. Estimation of the Vulnerability to Poverty}

Table 2 presents the estimated vulnerability to poverty for the respondents. Age squared $(\mathrm{P}=0.01)$, sex $(P=0.10)$, covariate shocks $(P=0.10)$ and farm size $(\mathrm{P}=0.05)$ were positive and significant in $e x$ antemean consumption while age $(\mathrm{P}=0.01)$, married respondents $(\mathrm{P}=0.10)$, and years of schooling $(\mathrm{P}=$ $0.05)$ were negatively significant in $e x$ ante mean consumption. The table showed that an increase in age squared will increase vulnerability to poverty by 0.0014 percent. This indicated that vulnerability to poverty increases as the age of the respondents' 
increases but this tendency decreases at an increasing rate as age advances. Sex was significant at 10 percent which indicated that vulnerability to poverty spikes as male head increases in the study area. This result negated the a-priori expectation. Vulnerability to poverty increases as covariate shocks increases in the study area. The coefficient of covariate shock was significant at 10 percent. So also, farm size increases vulnerability to poverty in the study area. This implied that a rise in farm size will increase vulnerability to poverty. The result negated the apriori expectation, an increase in farm size suppose to reduce vulnerability to poverty.

Vulnerability to poverty was found to be lower with less age; the coefficient of age was negatively significant at 1 percent, the result implied that an increase in age will reduce vulnerability to poverty in the study area. Also, the coefficient of married respondents was significant at 10 percent; this indicated that a rise in the married respondents will lower vulnerability to poverty. Likewise, years of schooling will reduce vulnerability to poverty of the respondents by 0.17 percent, the coefficient was found to be significant at 5 percent level of significance. The result was in line with the findings of Novignon (2010) in his work on estimating household vulnerability to poverty from cross section data: empirical evidence from Ghana where married head was found to lower vulnerability to poverty.

The result also showed that age squared $(P=0.01)$, sex $(P=0.01)$, number of family member above 18 year $(P$ $=0.01)$, household size $(\mathrm{P}=0.01)$, farm size $(\mathrm{P}=$ 0.01 ), idiosyncratic shocks $(P=0.10)$, covariate shocks $(\mathrm{P}=0.01)$ and economic shocks $(\mathrm{P}=0.05)$ were positively significant in ex ante variance consumption. This indicated that an increase in these variables will increase the vulnerability to future poverty in the study area. Also, age $(\mathrm{P}=0.01)$, married $(\mathrm{P}=0.01)$, years spent in school $(\mathrm{P}=0.01)$, distance to water $(\mathrm{P}=$ $0.01)$, health shocks $(\mathrm{P}=0.01)$ and agricultural shocks $(P=0.01)$ were negatively significant variables in ex ante variance consumption. This indicated that these variables lower vulnerability to future poverty in the study area. The result contradicted the findings of Awel, (2007) in his study on vulnerability and poverty dynamics in rural Ethiopia where he indicates that expected log consumption per adult equivalent is negatively influenced by household size.

Table 2 : Model for the Estimation of the Vulnerability to Poverty

\begin{tabular}{|lcccccc|}
\hline Variables & \multicolumn{2}{c}{ OLS Regression } & \multicolumn{3}{c|}{ FGLS Regression } \\
\hline & Coefficient & Std.Err & t & Coefficient & Std.Err & t \\
\hline Age & $-0.01380^{* * *}$ & 0.00396 & -3.48 & $-0.28058^{* * *}$ & 0.00006 & -4469.42 \\
\hline Age(squared) & $0.00014 * * *$ & 0.00004 & 3.63 & $0.00279 * * *$ & $6.00 \mathrm{e}-07$ & 4663.19 \\
\hline Sex & $0.02823 *$ & 0.01507 & 1.87 & $0.57089^{* * *}$ & 0.00024 & 2394.52 \\
\hline Household size & 0.00514 & 0.00486 & 1.06 & $0.10401 * * *$ & 0.00008 & 1352.82 \\
\hline Household size(sqd) & -0.00033 & 0.00026 & -1.25 & 0.00051 & 0.00054 & 0.95 \\
\hline Married & $-0.05408^{*}$ & 0.02868 & -1.89 & $-1.09884 * * *$ & 0.00045 & -2421.59 \\
\hline Age above 18 & 0.00244 & 0.00399 & 0.61 & $0.04939^{*} * *$ & 0.00006 & 780.7 \\
\hline Years of schooling & $-0.00171 * *$ & 0.00083 & -2.05 & $-0.03456 * * *$ & 0.00001 & -2619.49 \\
\hline Credit & -0.00843 & 0.01084 & -0.78 & $-0.17056^{* * *}$ & 0.00017 & -994.17 \\
\hline Distance to water & -0.00008 & 0.00028 & -0.30 & $-0.00171 * * *$ & $4.45 \mathrm{e}-06$ & -386.65 \\
\hline Economic Shocks & 0.19780 & 0.20413 & 0.97 & $0.00202^{* *}$ & 0.00084 & 2.40 \\
\hline Health Shocks & -0.19403 & 0.11990 & -1.62 & $-3.99998^{* * *}$ & 0.00189 & -2108.38 \\
\hline
\end{tabular}




\begin{tabular}{|lcccccc|}
\hline Agricultural Shocks & -0.24607 & 0.20403 & -1.21 & $-5.11969^{* * *}$ & 0.00323 & -1585.86 \\
\hline Covariate Shocks & $0.22138^{*}$ & 0.11892 & 1.86 & $4.55499^{* * *}$ & 0.00188 & 2420.77 \\
\hline Idiosyncratic Shocks & -0.01296 & 0.01639 & -0.79 & $0.02600^{*}$ & 0.01512 & 1.72 \\
\hline Farm size & $0.00156^{* *}$ & 0.00069 & 2.26 & $0.03183^{* * *}$ & 0.00001 & 2893.20 \\
\hline Constant & 10.51333 & 0.10810 & 97.25 & $110.411^{* * *}$ & 0.00171 & $6.5 \mathrm{e}+04$ \\
\hline $\mathrm{R}^{2}$ & 66.1 & \multicolumn{7}{c}{74.3} \\
\hline Observation & 1,009 & 1,009 & \\
\hline
\end{tabular}

$* * *$ significant at 1 percent, $* *$ significant at 5 percent and significant at $* 10$ percent

\section{Source: Author's estimates based on the GHS data 2012/2013.}

\section{Vulnerability and Poverty at Household Level and distribution by zone}

The poverty and vulnerability estimates based on generalized households' survey data are presented in Table 3, and its distribution by zone is presented in Table 4. From Table 3, results reveals that 42.4 percent households in the study area were poor while 57.8 percent households were vulnerable to become poor in future which was much higher than the point-in-time estimates of poverty, thus, signifies the importance of forward looking poverty analysis. The distribution of population by poverty status can be decomposed in vulnerable and non-vulnerable households indicating that 100 percent of poor household will still be poor in future. It is important to note that 584 households were both poor and vulnerable while 2 households ( 0.5 percent) were non-poor and vulnerable. The table showed that 428 households (99.5 percent) were non-poor and nonvulnerable while none of the poor households will exit poverty next year. The result negated the findings of Novignon (2010), in his study on estimating household vulnerability to poverty from cross section data: empirical evidence from Ghana where he showed that only 55.67 percent of their sampled respondents were poor and vulnerable. Table 4 showed that North East and North West were the most vulnerable to poverty in the study area with $69 \%$ of households in the zone were vulnerable to poverty. South East and South west has the high percentage of non-vulnerable households in the study area with 54\% and $52 \%$ respectively.

Table 3 : Vulnerability and Poverty at Household Level

\begin{tabular}{lrrl}
\hline Vulnerability & \multicolumn{2}{c}{ Poverty status } & \\
& \multicolumn{1}{c}{ Nonpoor } & \multicolumn{1}{c}{ Poor } & Total \\
\hline Non-vulnerable & $428(99.5)$ & $0(0.0)$ & $428(42.2)$ \\
Vulnerable & $2(0.5)$ & $584(100.0)$ & $586(57.8)$ \\
Total & $430(42.4)$ & $584(57.6)$ & $1,014(100.0)$ \\
\hline
\end{tabular}

Figures in parenthesis are Percentage

Source : Author's estimates based on the GHS data 2012/2013.

Table 4 : Vulnerability and Poverty at Household Level by Zones

\begin{tabular}{|l|l|l|l|}
\hline \multirow{2}{*}{ Zones } & \multicolumn{3}{|l|}{ Poverty Status } \\
\cline { 2 - 4 } & Non Poor & Poor & TOTAL \\
\hline North Central & & & \\
\hline
\end{tabular}




\begin{tabular}{|l|l|l|l|}
\hline Non-Vulnerable & $74(100.0)$ & $0(0.0)$ & $74(41.0)$ \\
\hline Vulnerable & $0(0.0)$ & $106(100.0)$ & $106(59.0)$ \\
\hline Total & $74(41.0)$ & $106(59.0)$ & $180(100.0)$ \\
\hline North East & & & \\
\hline Non-Vulnerable & $56(97)$ & $0(0.0)$ & $56(31)$ \\
\hline Vulnerable & $2(3.0)$ & $122(100)$ & $124(69.0)$ \\
\hline Total & $58(32.0)$ & $122(68)$ & $180(100.0)$ \\
\hline North West & & & \\
\hline Non-Vulnerable & $53(100.0)$ & $0(0.0)$ & $53(31.0)$ \\
\hline Vulnerable & $0(0.0)$ & $117(100.0)$ & $117(69.0)$ \\
\hline Total & $53(31.0)$ & $117(69.0)$ & $170(100.0)$ \\
\hline South East & & & \\
\hline Non-Vulnerable & $83(100.0)$ & $0(0.0)$ & $83(54.0)$ \\
\hline Vulnerable & $0(0.0)$ & $71(100.0)$ & $71(46.0)$ \\
\hline Total & $83(54.0)$ & $71(46.0)$ & $154(100)$ \\
\hline South South & & & $73(46.0)$ \\
\hline Non-Vulnerable & $73(100.0)$ & $0(0.0)$ & $87(54.0)$ \\
\hline Vulnerable & $0(0.0)$ & $87(100.0)$ & 160 \\
\hline Total & $73(46.0)$ & $87(54.0)$ & $89(52.0)$ \\
\hline South West & & & 170 \\
\hline Non-Vulnerable & $89(100.0)$ & $0(0.0)$ & \\
\hline Vulnerable & $0(0.0)$ & $81(100.0)$ & \\
\hline Total & $89(52.0)$ & & \\
\hline
\end{tabular}

Source: Author's estimates based on the GHS data 2012/2013.

\section{A. Estimate of vulnerability to poverty by shocks}

Table 5 presents the estimate of vulnerability to poverty by shocks. The shocks variables included were divided into a number of broad categories which includes; natural/agricultural; economic; political/social/legal; and demographic/life-cycle shocks that inflict welfare loss. Natural/agricultural shocks included flooding, drought, fire, earthquake but also erosion and pestilence affecting crops or livestock. Economic shocks included business closures, mass layoffs, job loss, wage cuts, loss of remittances and other reasons. Social shocks included court cases and bribery, as well as long duration general strikes, violence, crime and political unrest. Health/life-cycle shocks included death, injury and illness of household members. The survey distinguished between death of the primary income earner and death of other household members. Similarly, the respondents provided information whether the household was affected by idiosyncratic or covariate shocks and with the value of cost of burden.

Results as presented on Table 5 showed a crossdistribution of the percentage of vulnerability and poverty for the households who had suffered a welfare loss due to a shock during last five years, 2006-2010. The welfare loss is measured in terms of income loss which has resulted in consumption variability of food and non-food expenditure. 
Households and communities in Nigeria face the risks of suffering from different types of shocks that affect communities as a whole referred to as covariate shocks such as natural disasters while others affect one or a few households denoted as idiosyncratic shocks such as a death of household member or loss of a job. Even though, any household can be affected by these shocks, not all of them have the same probability of recovering from the consequences of suffering from them. Poor households were more vulnerable because they lack the necessary physical and human capital to recover from it.
The natural/agricultural is a common phenomenon whereby informal insurance mechanism failed; this is seen to have resulted in high poverty (80.9 percent) and vulnerability (89.4 percent). These estimates indicated that, the observed incidence of poverty underestimates the fraction of the population that is vulnerable to poverty. The level of underestimation is revealed by the vulnerability to poverty ratio, which is greater than one for all households in 2013.

Table 5 : Vulnerability and Poverty at Household Level

\begin{tabular}{lccl}
\hline Shocks & \multicolumn{2}{l}{ Vulnerability and poverty status } & $\begin{array}{l}\text { Ratio of Vulnerability } \\
\text { to poverty }\end{array}$ \\
& Vulnerable & Poor & \\
\hline Economic & 89.7 & 80.2 & 1.12 \\
Health & 7.9 & 10.1 & 0.78 \\
Natural/Agriculture & 89.4 & 80.9 & 1.11 \\
Idiosyncratic & 87.1 & 79.1 & 1.10 \\
Covariate & 8.1 & 9.6 & 0.84 \\
Social/political & 28.6 & 27.5 & 1.04 \\
\hline
\end{tabular}

Source : Author's estimates based on the GHS data 2012/2013.

\section{VI.CONCLUSION AND RECOMMENDATION}

The study revealed that income shocks and vulnerability to poverty explain the increasing incidence of poverty in the study area despite effort by successive Government to put an end to the menace. Policies concerning poverty reduction need to take into account the current non-poor households but who are vulnerable to poverty along with the poor households as well as income shocks faced by households.

\section{REFERENCES}

[1]. Adepoju, A.O., and Obayelu, O.A (2013). Livelihood diversification and welfare of ruralhouseholds in Ondo State, Nigeria. Journal of Development and Agricultural Economics. 5(12), 482-489

[2]. Alayande, B. and Alayande, O. (2004); "A Quantitative and Qualitative Assessment of Vulnerability to Poverty in Nigeria”. A Paper submitted for presentation at the CSAE Conference on Poverty reduction, Growth and Human Development in Africa, March,2004.

[3]. Amao, J.O., Ayantoye, K., and Fanifosi, G.E (2017) Analysis of poverty status and income Distribution among farming households In Imo State, Nigeria Journal of Economics and Sustainable Development 8(20), 190-200

[4]. Awel, Y.M (2007); "Vulnerability and poverty dynamics in rural". Ethiopia Master thesis 
forM.Phil in Environmental and Development Economics degree University of Oslo

[5]. Birhan S. and Testahun A. (2017); "Rural Households Vulnerability to Poverty in Ethiopia”.Journal of Poverty. 21(6), 528-542

[6]. Chaudhuri, S. (2003); "Assessing Vulnerability to Poverty: Concepts, Empirical Methods andIllustrative Examples". Mimeo, Columbia University, New York.

[7]. Chaudhuri, S. , Jalan J. and Suryahadi, A. (2002); "Assessing Household Vulnerability toPoverty from Cross-Sectional Data: A Methodology and Estimates from Indonesia".Discussion Paper 0102-52, Department of Economics, Columbia University.

[8]. Christiaensen, L. , \& Subbarao, K. (2004); "Toward an Understanding of HouseholdVulnerability in Rural Kenya”. World Bank Policy Research Working Paper 3326.

[9]. Dawit, M. (2015). Measuring vulnerability to poverty : an empirical evidence from Ethiopian rural household survey (ERHS). Second cycle, A2E. Uppsala: SLU, Dept. of Economics

[10]. Federal Republic of Nigeria. (FRN 2007). Legal notice on publication of 2006 census results. Federal republic of Nigeria official Gazette. 94(4)

[11]. Foster, J., Greer, J. and Thorbecke, E. (1984) A class of decomposable poverty measures,Econometrica,52, 761-766

[12]. Gaiha, R. , Imai K. , and Woojun, K. (2007); "Vulnerability and Poverty Dynamics in Vietnam".Economics Discussion paper No 0708.

[13]. Günther I. and Harttgen K. (2006); "Households Vulnerability to Covariate and Idiosyncraticshocks". (Preliminary Draft).

[14]. Isabel Günther and Johannes Maier (2013); "Poverty, Vulnerability, and Reference DependentUtility". World institute of development economics researcher working paper no2013/140
[15]. Jadotte, E. (2010) Vulnerability to Poverty: A microeconometric approach and application to theRepublic of Haiti departament d'Economia Aplicada University of Barcelona

[16]. Jamal H. (2009). “Assessing Vulnerability to Poverty Evidence from Pakistan". Social Policyand Development Center (SPDC), Pakistan.

[17]. Kasirye, I. (2007); "Vulnerability and Poverty Dynamics in Uganda" 1992-1999. MPRA PaperNo.8557.

[18]. Maharjan, K.L., and Joshi, N. P. (2009). Relationship between income-poverty and foodinsecurity in rural far-western Mid-hills of Nepal. Contributed Paper prepared forpresentation atthe International Association of AgriculturalEconomists Conference,Beijing, China, August 16-22, 2009

[19]. Landau, K., Klasen, S and Zucchini, W. (2012) "Measuring Vulnerability to Poverty Using Long-Term PanelData," Courant Research Centre PEG, 118,

[20]. Ligon, E. and L. Schechter (2003). Measuring vulnerability. Economic Journal 113, C95-C102

[21]. Mccarthy, Nancy; Brubaker, Josh; De La Fuente, Alejandro. 2016. Vulnerability to Poverty in rural Malawi (English). Policy Research working paper; no. WPS 7769. Washington, D.C. : World Bank Group. http://documents.worldbank.org/curated/en/939 091469543760391/Vulnerability-to-Poverty-inrural-Malawi

[22]. Novignon, J. (2010). Estimating household vulnerability to poverty from cross section data:empirical evidence from Ghana. Munich Personal RePEc Archive,https://mpra.ub.unimuenchen.de/39900/

[23]. Olaolu, M.O., Akinnagbe, O. M., and Agber, T. (2013). Impact of national fadama developmentproject phase (II) on poverty and food security among rice farming beneficiaries in 
KogiState, Nigeria. American Journal of Research Communication. 1(10), 280-295

[24]. Omonona B. T. (2001); "The Determinants of Poverty Among Farming Households in KogiState, Nigeria". Unpublished PhD Thesis, University of Ibadan, Ibadan, Nigeria.

[25].Oni, O. A., and Yusuf, S. A. (2006); "Determinants of Expected Poverty Among RuralHouseholds in Nigeria”. Research Paper No. 183. African Research Consortium,Nairobi.

[26]. Oni, O. A., and Yusuf, S.A. (2008); "Determinants of Expected Poverty Among Rural Householdsin Nigeria". Final report presented at the AERC Biannual Workshop in Nairobi, Kenya,December

[27]. Povel, F. ( 2015) Measuring exposure to downside risk with an application to Thailand and Vietnam. World Development 71: 4- 24.

[28]. Pritchett, L., Suryahadi, A. and S. Sumarto (2000); "Quantifying Vulnerability to Poverty: AProposed Measure, with Application to Indonesia". SMERU Working Paper, The World Bank, Washington.D.C.

[29]. Sen A. (1999), A plan for Asia's Growth: Asia's week, October 8, 25. Available at http://www.asisaweek.com/asiasweek/magazine/ 99/1008/viewpoint.html

[30]. Sisay T., Wondaferahu M., and Yilkau W. (2016); "Rural Households Vulnerability to Poverty inSouth West Ethiopia: The Case of Gulgel Gibe Hydroulic Dan Area of Sokoru and Tiro Afeta Woreda". Global Journal of Human Social Science E: Economics. 16(3), 44-54.

[31]. World Bank, (2012). An update to the World Bank's estimates of consumption poverty in the development in the developing world.

\section{Cite this article as :}

Adepoju A. A., Ayantoye K., Amao J. O., Akinjobi G. A., "Analysis of Vulnerability to Poverty and Income Shocks of Households in Rural Nigeria", International Journal of Scientific Research in Science and Technology (IJSRST), Online ISSN : 2395-602X, Print ISSN : 2395-6011, Volume 6 Issue 4, pp. 377-390, July-August 2019. Available at doi : https://doi.org/10.32628/IJSRST19668

Journal URL : http://ijsrst.com/IJSRST19668 